\title{
Publishing as a Graduate Student: A Quick and (Hopefully) Painless Guide to Establishing Yourself as a Scholar
}

Timothy S. Rich, Western Kentucky University

ABSTRACT Graduate students seldom know how to navigate the publishing process, yet a growing expectation is that new hires are capable of immediately producing publishable research as well as teaching. Considering the current state of the job market, graduate students should plan early to take advantage of the opportunities to publish early in their graduate career. This article provides suggestions for beginning the publishing process.

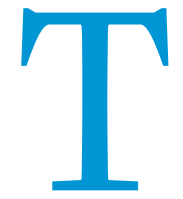

he mantra of "publish or perish" guides the decisions of many academics, yet graduate students seldom know how to navigate the publishing process. Juggling other commitments, graduate students still need to consider the process early in their program so that they can present a competitive publishing record when entering the job market. Whereas a decade ago publishing while in graduate school remained rare, today in most subfields of political science a peer-reviewed publication ${ }^{1}$ is considered a prerequisite for success on the job market. ${ }^{2}$ From large research-oriented universities to small liberal arts colleges, a growing expectation is that new hires are capable of immediately producing publishable research as well as teaching. Although a myriad of factors such as departmental reputation and teaching experience influence placement on a search committee's shortlist, publishing remains one of the clearest means for a candidate to positively influence this process. Considering trends in publishing and the current state of the job market, graduate students should plan early to take advantage of the opportunities to publish well before entering the job market.

\section{WHAT SHOULD I PUBLISH?}

Starting a research project and following through to submitting results to a journal is time intensive, especially if you are not already immersed in the relevant literature or have relevant data at hand in a usable format. Scholars in other fields have already highlighted the importance of initiating research early in their graduate career (e.g., Hansen 1991). To ease this process, I recommend that, from the start of graduate school, you should keep notes on possible research topics of interest. Often these notes will be a question or, at most a paragraph or two. As you progress in graduate school, you will routinely see overlooked areas or unanswered questions that interest you. Although you are unlikely to develop all of these ideas into research projects, writing down these ideas prevents you from forgetting what may be a good idea, especially

Timothy S. Rich is an assistant professor in the department of political science at Western Kentucky University. He can be reached at timothy.rich@wku.edu. ones in which you may not have the requisite substantive or methodological background to address properly.

Converting seminar papers into articles is also a common first step, however, not all seminar papers are destined for publication and even those with promise will likely require considerable revision before submission. Replicating an existing publication, either with additional cases or additional variables, is often another potential route (King 2006). After a general paper idea has been chosen (whether from a class or from scratch), the most important question to address is how will this work contribute to the existing literature. One way to think about this is to ask this question: what is the take-home message of this paper and what is the value added to the general literature on this topic? Contributions could be theoretical (e.g., challenging existing theory or testing such theories in a new way), methodological (e.g., quantitative analysis of a topic largely only addressed through qualitative means), the use of original data or case selection (e.g., a leastlikely case), or even a combination of these factors. Similarly, challenging the conventional wisdom has more appeal than reaffirming what is already accepted. If you cannot identify the "hook" in your paper, it is unlikely that reviewers will either. Thus, within the first or second paragraph, your contribution should be clear to potential readers.

Next, concentrate on one argument in the paper, rather than trying to address the vastness of a particular topic. You will be surprised how much can be written on what originally might appear to be a niche. Ask yourself what is the one point you want readers to remember and structure your paper so that both careful readers and casual skimmers can grasp this point. If sections of your paper distract from this main point, no matter how well written the section may be, remove them.

Because this should be original research, choose topics in which you already have a general understanding of the literature and a topic that sustains your interest. Ideally, you would like to enter the job market with a series of publications tightly related to your main research interest, as a group of unrelated publications may suggest a lack of focus and undermine any claims on your $\mathrm{CV}$ of a commitment to a main research interest. Connecting your first 
piece to a coherent research agenda is of some concern, but the larger concern should be the general time commitment of moving from research idea to published project. If you are not passionate about this project (e.g., an obscure seminar paper on a topic you are unlikely to revisit), investing the additional time prepping for publication is unwarranted.

After you have a potential research paper, follow the general format of published work in your subject area. Weingast (1995) is a good starting point. In general, papers should follow the structure of introduction, roadmap, literature review, research method, analysis, and conclusion. Some journals have an explicit format other than this one, yet following this format from the inception makes later edits for specific journals easier. Furthermore, not only does this formatting aid reading for those who are not immersed in your research topic (even if the reader is skimming the piece), but it forces you to remain on target. Subheadings should remain jargon-free. Because most journal articles follow the same pattern, following this basic format reduces the time needed to prepare the work for future publication. conference papers should not exceed 30 pages double-spaced and should be sent to the discussant at least a week before the conference, yet unfortunately, scholars frequently violate both of these common courtesies. Conferences range in terms of the number of presenters, the subfields or topics represented, and the receptiveness to interdisciplinary work. Unfortunately, feedback is often quite minimal; few in the audience (and unfortunately sometimes not even the discussant) have read the paper, relying primarily on the presentation itself. If you have presented a work with largely positive feedback, especially after multiple presentations, consider this a sign that your piece should be sent out for publication. Two additional points regarding conference presentations should be noted. First, presenting numerous conference papers that never result in publications potentially sends the undesired signal that you are unable to produce quality work (Van Cott 2005). In this regard, presenting the same paper multiple times with publication in mind is better than seeing conferences as the end goal (Cooper 2008). Second, often only after presenting a paper do you realize its major weaknesses, many of which may not be easy to

\section{Finally, before sending a paper to a journal for review, have colleagues and professors read it.}

Not only are they more likely to give it a thorough reading as they have a stake in your success, but the turnaround time from people who know you is usually much shorter than the months it takes to get reviewer comments. Some papers during this informal peer review fall apart at this point well before submission to a journal.

Finally, before sending a paper to a journal for review, have colleagues and professors read it. Not only are they more likely to give it a thorough reading as they have a stake in your success, but the turnaround time from people who know you is usually much shorter than the months it takes to get reviewer comments. Some papers during this informal peer review fall apart at this point well before submission to a journal. Perhaps your article is laced with too much jargon, with only those readers in your narrow subfield able to decipher and evaluate the piece. Perhaps nearly identical work has already been published, which unfortunately commonly occurs. Worse yet, your paper could be a rambling mess. Regardless, find this out from colleagues or professors who will most likely give suggestions on how to rectify these problems early rather than external reviewers who, while usually professional, have little reason to sugarcoat critiques to a stranger. Furthermore, have a diverse mix of people read early works, from those intimately familiar with the topic to those who have no background in your topic. For example, as a specialist in East Asian electoral politics, I often asked those in other subfields (e.g., American politics, public policy) to read my drafts to identify if the work was decipherable to the broader field. Asking for comments from a methodologically diverse group exposes potential weak points and ambiguous language. This review stage should not only gauge the paper's potential appeal to a larger audience, but provide suggestions as to venues for publication.

Another common avenue to gain feedback is to present at a conference, however, the overall usefulness of comments vary widely. Conference participation is a crucial aspect in preparing for the job market, especially in terms of concisely presenting your work (usually in 15 minutes or less) and in networking. Generally fix. There is no shame in deserting a project after a conference presentation.

\section{WHERE SHOULD I SEND MY WORK?}

There is no perfect answer to this question, but consider journals in which you expect the largest number of people interested in your topic will potentially read the paper. In publishing, your goal is hopefully to have an impact on current debates, and publishing in a journal in which experts in your subfield read is the best means to make such an impact.

With the proliferation of journals, deciding the best venue can be an onerous task. Here are a few broad factors to consider. First, identify what sort of audience would be interested in your paper. If it deals with broad issues that would appeal to a large swath of the discipline or subfield, then shooting for one of the broader journals is not unreasonable. However, if the topic is a niche that admittedly only a small number of scholars would find interesting, then submitting to a journal known specifically for that niche makes more sense. Skimming articles from the past five years in a variety of journals should give you some sense of the expectations in terms of quality and style and thus a better gauge of which journals may be interested in your piece. If a journal has recently published something similar on your topic in the past few years, attempt to cite this work; many journals ask the recently published authors to review articles. After you choose a journal for submission, tailor the paper based on the journal's particular theoretical, methodological, or interdisciplinary focus to encourage positive reviews or at least minimize negative remarks.

Second, consider general reputation of the journals. In theory, you want your piece placed in the most highly regarded journal 
that would possibly accept it. Remember that even solid works are often rejected from first-tier journals because of the finite space for print, the large number of submissions, or what appears, from the author's perspective, as arbitrary or superficial reasons. In these cases, consider a second-tier journal. In addition, just because you have not heard of a journal before is not necessarily an accurate measure of its quality. Many newer journals, some with prominent editors, produce high-quality work but receive far fewer submissions. Remember that not all peer-reviewed journals are equal nor will these likely be evaluated equally on the job market.

Third, consider the turnaround time. Journals commonly post their average turnaround time from when papers are submitted to when they expect to have reviews to the author. Most target for about three months, but this can vary significantly and often independently from the reputation of the journal itself. For example, Yoder and Bramlett (2011) identify a range from 21 to 118 days as the average turnaround time of journals that responded to their survey. Other than desk rejects-where the editor declines to send out the paper for review based usually on its poor fit for the theme of the journal-having a decision on a paper in less than two months is rare. In contrast, horror stories abound of waiting six months or more, with the end result little more than a paragraph panning the work. For example, once I waited seven months to receive a rejection that included the especially helpful one-line reviewer critique of "he uses someone else's data" (in that case a publicly available dataset). On another occasion I waited 10 months
Style) and often suggest limitations on the number of tables and figures. Specifications vary, but most journals also limit the length of submissions from 8,000 to 10,000 words or about 25 to 30 pages. Ignore these limitations at your own peril as you risk irritating both the editor and reviewers. Generally, shorter papers are both easier to review and to allocate limited space in journals. Use this to your advantage. Word limits, in particular, should encourage writers to develop a clear and concise style that ultimately results in a paper accessible to a wider audience. When in doubt, if a sentence or section is not crucial to the main argument of the paper, strongly consider cutting it.

\section{I'VE SENT OFF MY WORK. NOW WHAT?}

Wait. And wait some more. If you are motivated, start on another paper. Assistant professors commonly have multiple articles under review at a time to meet tenure requirements. Often data collected for one paper in mind is amenable to additional projects. Similarly, many graduate students find that data that failed to be incorporated into their dissertation finds a second life through side papers. By starting an additional project within the same basic literature, the time for preparing a paper for submission is shortened. Although you might not be prepared for multiple submissions, the lag between submission and a decision provides time to focus on other endeavors, such as your dissertation and teaching. If after three or four months you have heard nothing, contact the editor to inquire about the status. Occasionally editors will

\section{Word limits, in particular, should encourage writers to develop a clear and concise style that ultimately results in a paper accessible to a wider audience. When in doubt, if a sentence or section is not crucial to the main argument of the paper, strongly consider cutting it.}

for reviews which all pointed out flaws that had been rectified since submission (due to presenting at several conferences over that time). ${ }^{3}$ If time is crucial (e.g., you are planning to go on the market within the year), finding a journal known for a faster response time is a wise move. Few search committees are impressed by a CV listing papers under review, even if your intention is to signal productivity.

Finally, be realistic. Although every graduate student would love to have an article in a top-tier journal, this is unrealistic unless you have something above and beyond simply an interesting idea. Thus, when colleagues and professors suggest a journal that is not in the upper echelon, this should not be interpreted as a mistake on their part ("Oh, they just didn't get it"), but most likely an accurate evaluation. After all, professors have not only published in these journals, but in many cases have been reviewers for these same journals. Newer journals generally receive fewer submissions and may be a good avenue for your first submission. That said, there is little cost other than time in sending out a paper to a top journal and hoping for the best, expecting in reality to get feedback that will allow a revised version to be published in a slightly less prestigious journal.

After choosing a journal, pay careful attention to the submission requirements. Most journals have an explanation of submission requirements in the journal or on their website. The requirements define a style for citation (e.g., Chicago Manual of tell you how many reviews have been received and even release these before a final decision has been made. Other journals may ask if you can recommend potential reviewers. Both of these practices remain rare but may become more commonplace. In the meantime, develop a thick skin. Everyone at some point receives highly critical reviews, constructive or otherwise, and learning to properly respond to these reviews is a skill. With each submission, you should get better at anticipating problem areas (which, not surprisingly, are often the same areas addressed by colleagues and conference discussants).

After reviews come in, your paper will likely fall in one of three categories: accept with minor revisions, reject, and revise/resubmit (R\&R). Rejections are commonplace, even with relatively positive reviews. In fact, many good papers will be rejected multiple times before finding an appropriate outlet, taking a year or more before publication. If reviews are uniformly negative (and negative for the same reasons), it may indicate the end of the road for this paper. While papers are often submitted that are not developed to their full potential or would be more convincing with significant rewriting, not all papers are destined for publication. Realizing the sunk costs in dead-end papers is part of the process.

The category of revise and resubmit is the purgatory where often decent papers struggle to reach publication. Whereas in years past an R\&R almost certainly indicated future publication in that journal (assuming that suggested revisions were addressed), 
increasingly $R \&$ Rs in top journals are an invitation to a second round of revision, albeit with a greater yet undefined chance of publication. If the revisions are workable, address these quickly and resubmit the paper (in under a month if possible). In contrast, if the revisions are extensive, withdrawing the paper and submitting elsewhere remains an option. Keep in mind that for papers in a niche research area, the likelihood of receiving one of the same reviewers again at a different journal is common, thus ignore reviewer suggestions at your own risk.

When making revisions, synthesize the reviewers' comments and address each point as clearly as possible in the revised paper. Presume that any misinterpretations by reviewers are because of your lack of clarity rather than their ignorance or inability to realize your brilliance. We commonly presume that everyone in the discipline understands our niche's jargon, only realizing our errors when others read our work. After careful revision, include a page to the editor detailing these points, so that the editor can easily identify what changes have been made. Not only does this make the editor's job easier, but also signals that you took the reviewers' comments seriously, even if you did not implement all of the suggested changes.

\section{OTHER SUGGESTIONS}

The demands for publishing in both time and effort may seem daunting, but several factors can be more manageable. First, considering eventual publication when initially writing seminar or conference papers simplifies the process. Second, consider coauthoring, although this does not necessarily reduce time commitments or frustrations. Coauthoring has long been the norm in the natural sciences and is increasingly common in the social sciences. This strategy potentially allows you to combine individual research strengths, and ideally this should be evident within the final work. However, be cautious in coauthoring when your main contribution consistently is only methodological rather than substantive, even if you are attempting to market yourself as a methodologist. Similarly, although coauthoring with an advisor certainly will aid in generating name recognition, there is a tendency to assume that the student contributed considerably less to the project regardless of whether this accurate. Another option is collaborating with fellow graduate students either at your home university or elsewhere as this overcomes some of the potential biases in coauthoring with faculty. Ultimately, producing at least one solo-authored publication signals your ability to independently conduct research, while coauthored pieces produces slightly different signals, namely the ability to collaborate.

\section{CONCLUSION}

Disseminating one's work is a crucial component for success in academia. As publishing demands increase, graduate students must prepare accordingly to be competitive on the job market. Although the venues for publication increase, and the path to acceptance is a stochastic process, the actual preparation for publication remains remarkably similar across outlets. With a thick skin and an appreciation for the standards of publication, graduate students can certainly find outlets for their work.

\section{NOTES}

1. This article focuses on peer-review publishing. Many other publishing options exist for graduate students, from book reviews and short articles in newsletters to journals in which the editor has sole discretion on publication. While the value of nonreview publications varies greatly by search committee (Polsky 2011), the same general rules apply.

2. In an analysis of the 2001-2002 job market, Lopez (2003) makes little mention of graduate publication as an indicator of market success. Within a decade, publications became increasingly important for an initial interview (see Jaschik 2009). From my own nonscientific survey of colleagues on the market in recent years, I knew of only a scant few who received a job offer without at least a coauthored publication. The importance of publishing in graduate school is not limited to the social sciences. Mangematin (2000) finds that among engineering graduate students that publications correlate with success in academia.

3. Several colleagues have suggested that in cases like this authors can ask the editor to reconsider the submission, especially if there is clear evidence of revision. There appears to be a fine line between politely requesting reconsideration and irritating what is commonly an overworked editor. In my case, I opted to send the paper elsewhere.

\section{REFERENCES}

Cooper, Christopher A. 2008. "Reassessing Conference Goals and Outcomes: A Defense of Presenting Similar Papers and Multiple Conferences." PS: Political Science and Politics 41 (2): 293-95.

Hansen, W. Lee. 1991. "The Education and Training of Economics Doctorates: Major Findings of the Executive Secretary of the American Economic Association's Commission on Graduate Education in Economics." Journal of Economic Literature 29 (3): 1054-87.

Jaschik, Scott. 2009. "Job Market Realities." Inside Higher Ed September 8. http:// www.insidehighered.com/news/2009/o9/o8/market

King, Gary. 2006. "Publication, Publication." PS: Political Science and Politics 39 (1): $119-25$.

Lopez, Linda. 2003. "Placement Report: Political Science Ph.D.s and ABDs on the Job Market in 2001-2002." PS: Political Science and Politics 36 (4): 835-41.

Mangematin, V. 20oo. "PhD Job Market: Professional Trajectories and Incentives during the PhD." Research Policy 29: 741-56.

Polsky, Andrew J. 2011. "Preparing for an Academic Career: Some Suggestions for Graduate Students." Unpublished Paper.

Van Cott, Donna Lee. 2005. "A Graduate Student's Guide to Publishing Scholarly Journal Articles.” PS: Political Science and Politics 38 (4): 741-43.

Weingast, Barry R. 1995. "Structuring Your Papers (Caltech Rules).” Unpublished paper. Available at: www.stanford.edu/group/mapss/colloquium/papers/ caltech.pdf.

Yoder, Stephen, and Brittany H. Bramlett. 2011. "What Happens at the Journal Office Stays at the Journal Office: Assessing Journal Transparency and RecordKeeping Practices." PS: Political Science and Politics 44 (2): 363-73. 